\title{
Introduction: The intellectual history of election studies
}

\author{
JACQUES THOMASSEN \\ University of Twente, The Netherlands
}

The main purpose of this special issue is to document the intellectual history of national election studies in Europe. A programme of regular election studies has developed in Denmark, (West-) Germany, Great Britain, the Netherlands, Norway and Sweden. The beginning of such a programme can be observed in Belgium, while several election studies have also been conducted in France and Spain on a more irregular basis. Because of the historical perspective it might seem logical to limit this issue to the aforesaid six countries with an established tradition of election studies. However, this would not do justice to developments elsewhere. Particularly in France, numerous election studies with a specific intellectual framework have been conducted, even though France does not have a regular programme of election studies.

Furthermore, the intellectual history of election studies in Europe can hardly be written without telling the history of the American National Election Studies as well. The influence of the Michigan School, and of a specific group of scholars - Angus Campbell, Philip Converse, Warren Miller and Donald Stokes - on the development of electoral research in Western Europe can hardly be overestimated. This is not only because The American Voter became the major source of intellectual inspiration for electoral research in Europe and elsewhere, but also because the Michigan group took part in the establishment of a programme of national election studies in a number of West European countries. As Warren Miller explains in his contribution to this volume, the development of a comparative programme of election studies was a deliberate effort by the Michigan group because studying the influence of institutional settings on electoral behaviour was one of the early objectives of the Michigan programme.

On the European side, young scholars were more than eager to learn the tricks of the trade. A whole generation of European scholars in the field of election studies made the pilgrimage to the Mecca of the study of political behaviour, the Survey Research Center and its center tor political studies at the University of Michigan. Therefore, in many cases the influence of the Michigan School was direct and personal. As early as 1958-1959 Angus Campbell was a visiting professor in Oslo. Donald Stokes, together with David Butler, founded the British Election Studies. Together they wrote Political Change in Britain, still considered to be the classic in British electoral behaviour research. Philip Converse had a hand in the preparation of the 
1965 Norwegian election study, cooperated with George Dupeux in the 1960s, and wrote with Roy Pierce the monumental volume Political Representation in France, part of which can be considered as an election study along the traditional Michigan lines. But the most active of the Michigan scholars on the European front has been Warren Miller. His regular and sometimes lengthy visits to the Scandinavian countries (Sweden in particular), Britain, the Netherlands and West-Germany have had a lasting influence on the programme of election studies in these countries. Therefore, having Warren Miller as the author of the first article of this special issue is not only an intellectual necessity, but also a tribute to the godfather of most of the flourishing European national election studies programmes.

The idea for this issue was born when three of the contributors to this volume (Curtice, Van der Eijk and the present author) were fellows at NIAS in 1988-1989. First drafts of the present contributions were presented at a conference at the University of Twente in 1990. The major reason to consider the publication of this issue was the observation that, despite a flourishing industry of national election studies, the development of comparative research in the field of electoral studies is relatively poor. For a number of reasons this observation might sound counterintuitive.

First, the contributions to this issue are ample evidence for the extent to which national election studies in Europe are based on the common heritage of the Michigan studies. Miller, in his contribution, recollects how the Michigan group deliberately stimulated electoral research in Europe in order to create a basis for comparative electoral research. A whole generation of European researchers was trained at Michigan. Therefore, one might expect that this common intellectual background would lead to the development of common concepts and measurement instruments in those countries where election studies came into existence under such comparable and favourable conditions for comparative research.

Second, one might easily argue that electoral behaviour is one of the best developed areas in the field of comparative politics. Numerous books, articles, conferences and even a specialized journal (Electoral Studies) bear witness to this. Lipset and Rokkan (1967), Rose (1974), Dalton, Flanagan and Beck (1984) and Franklin et al. (1992) are only the best known examples of a long list of comparative volumes and articles. These and a great number of other publications prove that there is a flourishing community of scholars in the Western world who have cooperated intensively over the years. It is obvious, although more difficult to demonstrate, that they have influenced each other over the years. And yet, none of this can hide the fact that there is no such thing as a well developed programme of comparative electoral research. Mutual influences are mostly not the result of regular and systematic debates on the development of the field, let alone of a common platform from which common concepts and instruments of measurement are developed. Much as they have in common, the different national election 
programmes are first of all national ones. One might call it a 'paradox that while the field of electoral research is among the oldest, and certainly most developed areas of empirical social research, it has not generated the kind of large-scale cross-national survey projects which have been so successful in the development of other areas of comparative mass political behaviour' (Van der Eijk \& Schmitt 1991: 260).

Despite a well developed programme of national election studies in several countries there is no well-matched competitor in the field of electoral behaviour to the really comparative studies of political participation (Verba et al. 1978; Barnes \& Kaase 1979) or the political culture (Almond \& Verba 1963; Inglehart 1979, 1990). Without any doubt one of the major reasons for this situation is that there are a great many obstacles to the use of the various national election studies in cross-national research. The user of these data has to identify which suitable questions have been asked in which country and when. At the moment this can only be done by looking separately through the documentation for each country - which varies in format from one to another and which may not be available in a widely understood language. Next the researcher has to acquire the relevant datasets - which may not all currently be available in the researcher's own national data archive (Curtice 1992: 2). And even if one has the stamina to take all these hurdles one will probably discover that even where comparable concepts can be found in different studies, valid comparisons can still hardly be made because the instruments of measurement are not really comparable, for instance because question wordings are slightly different. It is no wonder that, where truly comparative work has been done, it is based, not on the well established national election studies, but on truly comparative surveys like the Eurobarometer.

Therefore, the conclusion is inevitable that, despite great intellectual and financial investments in national election studies, the development of comparative research on the basis of these studies is less than satisfactory. The view held by the Michigan group in the 1960s is as valid as ever - that the essential uniqueness of the discipline of political science is to be found in the need to understand the contributions, the roles, and the impact of the institutions of politics and government (Miller, in this issue). In practice the only way to analyse the effects of institutional differences on political behaviour is by comparative research. The examination of any relationship requires variance in both the independent and the dependent variable. Yet many independent variables of interest to electoral analysts, such as media structure or legal rules, only vary between countries and not within them. Therefore, many of the relationships in which electoral researchers are interested can only be investigated satisfactorily on a cross-national basis (Curtice 1992: 1).

These considerations led to the foundation of the International Committee for Research into Elections and Representative Democracy (ICORE) in 1989. It is the objective of ICORE to develop an easily accessible data base for those who want to do comparative research, but also to offer a platform 
for a regular debate on the intellectual development of electoral research. A condition for an effective intellectual debate on the future of comparative electoral research asks for a mutual knowledge of the intellectual and organizational history of national election studies. In this sense one might see this issue as one of the stepping-stones to a programme of comparative electoral research.

When composing an issue like this it is difficult to decide which is the lesser of two evils. When each author is given the opportunity to write his contribution from his own idiosyncratic perspective, the common denominator of the different election studies might disappear from our view. On the other hand, by imposing a detailed common framework on the authors one runs the risk of exaggerating the similarities and underestimating the differences between the countries. In order to find a compromise between these two extremes, a general framework was given to the authors. This provided a very short general history of electoral research in Western societies that by necessity is more abstract than the specific history in each separate country. Deviations from this guideline should reflect a different pattern in the country concerned and not the personal hobby of an individual author.

This short general history of election studies as it was presented to the authors can be summarized in a few sentences. It starts with the studies that were conducted by Paul Lazarsfeld and his associates in the 1940s and are usually referred to as the Columbia studies (after Columbia University whose Bureau of Applied Social Research employed Lazarsfeld). The Columbia School is generally labelled as the prototype of the sociological approach according to which the membership of social groups determines the vote to a great extent. Because these social predispositions will hardly change during a voter's lifetime they are responsible for a certain degree of stability in voting behaviour. This traditional characterization of the Columbia School is not incorrect but does little justice to the original design of the Columbia studies. What Lazarsfeld and his associates intended to do in their original study was to follow the development of voting-intentions during the election campaign. Only after they had found out that few voters did change their voting intention during the campaign did they develop the sociological model that was the central theoretical focus in their second major publication (Berelson et al. 1954).

In at least a few European countries (UK, the Netherlands, Sweden) early election studies were modelled after the original study design of the Columbia School, but its influence did not last very long. Before a programme of election studies could reach maturity in any of the European countries, the new wisdom of the Michigan School made its glorious entrance in Europe not long after, and in some cases even before, The American Voter was published (Campbell et al. 1960).

For a long time there was no other theoretical model that could compete with the Michigan model. However, this is not to say that every aspect of the model was enthusiastically embraced. The concept of party identification 
in particular has never achieved the same central position in European electoral research as in America. One of several reasons for this is that more than in the United States a sociological approach, in which the social cleavage structure played a central role, kept its importance in Europe. More than once it was questioned whether party identification could add anything to our understanding of the relationship between social predispositions and the vote (Budge et al. 1976). However, the persistence of the sociological approach can hardly be attributed to a lasting influence of the Columbia School, but rather to Lipset and Rokkan's classic volume on the relationship between the development of the party system and the social cleavage structure, compressed in their famous dictum that 'the party systems of the 1960s reflect, with but few significant exceptions, the cleavage structure of the 1920s' (Lipset \& Rokkan 1967: 50).

What the Michigan School and the sociological approach have in common is their emphasis on long-term predispositions. The importance of such predispositions was hardly questioned at the end of the 1950s and the early 1960s when the foundations for a programme of election studies were laid in most West European countries. However, as it turned out, the stability of the party system and of individual voting behaviour for which these longterm predispositions were held responsible, started to crumble almost at the same time as a regular programme of election studies came into existence. The declining importance of the traditional cleavage structure and the increasing volatility of voting behaviour came as a surprise to electoral researchers, to the extent that even the terminology of the changing political reality was completely dictated by the reality of the past. Where more or less lasting alignments had been considered the normal pattern in the first half of this century, the new development was described as dealignment. And where lasting alignments were considered the normal pattern almost a generation of scholars has been searching desperately for patterns of realignment.

However, no indisputable realignment has materialized. Therefore, where the importance of long-term predispositions was declining the attention was bound to shift to short-term factors. The major short-term factors are issue opinions and candidate preferences. In this context rational choice theories reappeared prominently on the research agenda. The rationality of voters, that is to say the extent to which voters would vote for the party that best represents their policy preferences, had been seriously questioned since the early election studies. However, the declining importance of long-term attachments and growing levels of education have led to the supposition that a growing number of voters have the level of sophistication that enables them to compare political parties in terms of their policy programmes.

Summarizing, the authors were asked to write the intellectual and organizational history of election studies in their country, and to pay attention to the influence of the Columbia School, the introduction of the Michigan School 
(when and to what extent it was implemented; problems with the applicability of the model; the usefulness of core concepts as party identification), and the development of rational choice models. They were also asked to relate this intellectual history to social and political changes, in particular the changes in the cleavage structure and the party system, and the growing sophistication and volatility of the electorate.

The authors were invited to end with an indication of new developments and the challenges for future research. For obvious reasons no indication was given what the content of this last section should be. But, retrospectively at least, a few words can be said about these developments and challenges.

An emerging development is the tendency 'of returning to the theoretical roots' in the sense of a growing awareness 'that with national random samples the social fabric in which the individual is integrated - family, friends, groups and clubs, the work place - in one word, the regional or local context is systematically excluded from the analysis' (Kaase \& Klingemann, in this issue). More generally, a tendency to expand the scope of election studies to cover the interaction of different actors in the electoral process can be observed in almost every country. The most ambitious expression of this tendency can be found in Holmberg's description of the development of election studies in Sweden: 'The idea was to make, what has always been called election studies, into real election studies by supplementing the voter surveys with research on other important electoral actors, such as the media, the political parties, candidates, and the elected representatives. The ultimate goal is to make it possible to study the electoral interaction between these actors across time, i.e. to study the functioning of elections in a representative democracy'.

This programme reflects a general understanding that the ultimate objective of electoral research is to contribute to the understanding of the functioning of representative democracy. This, of course is nothing new. The first sentence of Berelson's famous last chapter in Voting (1954) reads as follows: 'What does all this mean for the political theory of democracy?' In his view the major finding that individual citizens in general did not meet the requirements set by classic democratic theory, meant that the requirements of normative democratic theory should be changed. Berelson's attempt to revise democratic theory on the basis of empirical research has been refuted repeatedly and has become used as a case in point of a naive democratic elitism. Ever since V.O. Key's famous judgement that 'the electorate behaves about as rationally and responsibly as we should expect, given the clarity of the alternatives presented to it and the character of the information available to it' (1966: 7), it has been argued that the extent to which individual voters will behave rationally and responsibly will not only depend on characteristics of the voters, but also on the behaviour of other actors within the political system. The extent to which 'the political system matters' (Granberg \& Holmberg 1988) can only be assessed by comparative research. Only the development of such a programme of comparative research can ensure that 
the acronym ICORE (International Committee for Research into Elections and Representative Democracy) will become a valid indication of the work of the international scholarly community.

\section{References}

Almond, G.A. \& Verba, S. (1963). The Civic Culture: Political Attitudes and Democracy in Five Nations. Princeton: Princeton University Press.

Barnes, S.H. \& Kaase, M. (1979). Political Action: Mass Participation in Five Western Democracies. Beverly Hills: Sage.

Berelson, B., Lazarsfeld, P.F. \& McPhee, W.N. (1954). Voting: A Study of Opinion Formation in a Presidential Campaign. Chicago: University of Chicago Press.

Budge, I., Crewe, I. \& Farlie, D., eds., (1976). Party Identification and Beyond: Representations of Voting and Party Competition. London: Wiley.

Butler, D. \& Stokes, D. (1969). Political Change in Britain. London: MacMillan.

Campbell, A., Converse, P.E., Miller, W.E. \& Stokes, D.E. (1960). The American Voter. New York: Wiley.

Converse, P. \& Pierce, R. (1986). Political Representation in France. Cambridge: Harvard University Press.

Curtice, J. (1992) Paper presented at ICORE-meeting, Cologne, December 1992.

Dalton, R.J., Flanagan, S.C. \& Beck, P.A., eds. (1984). Electoral Change in Western Democracies: Patterns and Sources of Electoral Volatility. Princeton: Princeton University Press.

Franklin, M., Mackie, T. \& Valen, H. (1992). Electoral Change: Responses to Evolving Social and Attitudinal Structures in Western Countries. Cambridge. Cambridge University Press.

Granberg, D. \& Holmberg, S. (1988). The Political System Matters: Social Psychology and Voting Behavior in Sweden and the United States. Cambridge: Cambridge University Press.

Inglehart, R. (1977) The Silent Revolution: Changing Values and Political Styles Among Western Publics. Princeton: Princeton University Press.

Inglehart, R. (1990). Culture Shift in Advanced Industrial Society. Princeton: Princeton University Press.

Key, V.O. Jr. (1966). The Responsible Electorate. Cambridge: Harvard University Press.

Lipset, S.M. \& Rokkan, S. (eds.) (1967). Party Systems and Voter Alignments: Cross-National Perspectives. New York: The Free Press.

Rose, R., ed. (1974). Electoral Behavior: A Comparative Handbook. New York: The Free Press.

Van der Eijk, C. \& Schmitt, H. (1991). The role of the Eurobarometer in the study of European elections and the development of comparative electoral research, in K. Reif \& R. Inglehart (eds.), Eurobarometer: The Dynamics of European Public Opinion. Essays in Honour of Jacques-René Rabier. London: MacMillan.

Verba. S.. Nie, N.H. \& Kim. J. (1978). Participation and Political Equality. Cambridge: Cambridge University Press.

Address for correspondence: Prof. Jacques Thomassen, Faculty of Public Administration \& Public Policy, University of Twente, P.O. Box 217, 7500 AE Enschede, The Netherlands Phone: (53) 893270 ; Fax: (53) 356695 